\section{Physical-mechanical properties and bonding quality of heat treated poplar (I-214 clone) and ceiba plywood}

\author{
Giacomo Goli ${ }^{(1)}$, Corrado Cremonini ${ }^{(2)}$, Francesco Negro ${ }^{(2)}$, Roberto \\ Zanuttini $^{(2)}$, Marco Fioravanti ${ }^{(1)}$
}

The present paper investigates the physical and mechanical modifications of both poplar ( $1-214$ clone) and ceiba veneers and plywood after heat treatments of different intensities ( 5 and $7 \%$ of dry mass losses). Plywood panels were glued before and after heat treatment with urea-formaldehyde (UF) and melamine-urea-formaldehyde (MUF) resins. In order to assess the effects of treatments on both the wood and the glues, the dry mass, the density, the bending strength, the Young's modulus and the bonding quality were measured before and after heat treatment. Different treatments were compared as well. Results showed that the loss in cell wall polymers due to the heat treatment caused a significant reduction of the equilibrium moisture content of samples. From a mechanical point of view, the treatment resulted in an important reduction of strength and in a small reduction of stiffness. Bonding quality and mechanical properties were widely affected by the heat treatment. The different intensities of treatments applied (the treatment range was up to $5 \%$ and $7 \%$ of dry mass loss) did not show significant differences for most of the features assessed. The mechanical performance and the bonding quality of treated samples suggested that veneers should be glued after heat treatment. Apparent cohesive wood failure revealed that different degradations affect wood and glues with a prominent effect on glues for UF resins and a prominent effect on the wood for MUF resins.

Keywords: Heat Treatment, Poplar, Ceiba, Plywood, Bonding Quality, Physicalmechanical Properties

\section{Introduction}

Heat Treatment $(H T)$ represents one of the possible solutions applied in order to permanently modify wood properties. According to various review articles (Kamdem et al. 2002, Finnish ThermoWood Association 2003, Navi \& Sandberg 2012, Sandberg et al. 2013) $H T$ is currently applied to timbers both from broadleaves (beech, ash, poplar) and coniferous species (spruce, pine). In particular, the change of water-related properties of heat-treated poplar was recently studied by Bak \& Németh (2012), who showed that a treatment at $160{ }^{\circ} \mathrm{C}$ reduced the equilibrium moisture content.
$H T$ results in relevant modification of the physical and mechanical properties of wood. From a physical point of view, moderate $H T$ results in a reduction of density, a reduction of equilibrium moisture content (EMC), an improvement of dimensional stability, an improvement of the decay resistance to Fungi and in a darkening of wood natural color. From a mechanical point of view, moderate $H T$ results in a reduction of bending strength, in small variations of stiffness, in an imstrength.

Of great interest to the present work are the effects produced by $H T$ on the main constiproved hardness and in a reduction of shear

$\square$ (1) GESAAF, University of Florence, v. S. Bonaventura 13, I-50145 Firenze (Italy); (2) DiSAFA, University of Turin, v. L. da Vinci 44, I-10095 Grugliasco (TO - Italy)

@ Francesco Negro (francesco.negro@unito.it)

Received: Feb 24, 2014 - Accepted: Sep 11, 2014

Citation: Goli G, Cremonini C, Negro F, Zanuttini R, Fioravanti M, 2014. Physical-mechanical properties and bonding quality of heat treated poplar (I-214 clone) and ceiba plywood. iForest 8: 687-692 [online 2014-12-17] URL: http://www.sisef.it/iforest/contents/? id=ifor $1276-007$

Communicated by: Marco Borghetti

tutive polymers of the cell wall. The losses of hygroscopic hemicelluloses, converted into furan base polymers, predominantly furfural and hydrossymethilfurfural (Navi \& Sandberg 2012), have on $H T$ wood two main effects: a reduction of the total shrinkage and a reduction of wood mass according to the treatment intensity. The losses of dry mass make the material lighter and suitable for the production of very light wooden products if low density wooden species, e.g., poplar (Populus sp.) and ceiba (Ceiba pentandra (L.) Gaertn.), are chosen as the base material to be treated.

Rather limited is the literature available regarding applications of $H T$ to wood derivatives, in particular to plywood. Experimental studies were conducted on laminated beams by Sernek et al. (2008) and Poncsák et al. (2007), and on oriented strand boards (OSB) with strands treated before gluing by Paul et al. (2006). Tests on the mechanical characteristics of $H T$ poplar laminated veneer lumber $(L V L)$ were carried out by Nazerian \& Ghalehno (2011) and other studies on the mechanical resistance of silver nanoparticles-impregnated poplar were conducted by Taghiyari (2011). Conversely, no information is available about $H T$ on ceiba wood and its derivatives.

The present work aims to investigate the possible application of $H T$ to poplar and ceiba plywood in order to improve their dimensional stability, durability and water repellency, all essential requirements to make these products suitable for external use.

Main goals of the experimentation were to determine if $H T$ can be considered consistent with the glues actually used for plywood production and if $H T$ should be better applied on veneers or directly on the glued panels.

In order to achieve these goals, poplar and ceiba veneers and plywood were heat treated at $180-190{ }^{\circ} \mathrm{C}$ up to a reduction of $5 \%$ and $7 \%$ of the initial dry weight. The treatments

Box 1 - List of abbreviations.

The following abbreviations are used throughout the text:

- SEC: standard environmental conditions, $20{ }^{\circ} \mathrm{C}$ and $65 \% \mathrm{RH}$;

- ODS: oven dry state, $103 \pm 3{ }^{\circ} \mathrm{C}$;

- $M_{0}$ : untreated oven dry mass $[\mathrm{kg}]$;

- $M_{12}$ : untreated mass at $S E C[\mathrm{~kg}]$;

- $M L_{0}$ : mass loss because of thermal treatment at $O D S$ referred to $\mathrm{M}_{0}[\%]$;

- $M L_{12}$ : mass loss at $S E C$ because of thermal treatment referred to $\mathrm{M}_{12}[\%]$;

- $\rho_{12}$ : untreated density at $S E C\left[\mathrm{~kg} \mathrm{~m}^{-3}\right]$;

- $\rho L_{12}$ : density loss because of thermal treatment at $S E C$ referred to $\rho_{12}[\%]$;

- $f_{\mathrm{v}}$ : shear strength;

- $A C W F$ : apparent cohesive wood failure 
Tab. 1 - Material subjected to heat treatment. The group codes indicate: species product glue. (Species): poplar or ceiba; (product): panel $(\mathrm{P})$ or veneer $(\mathrm{V})$; (glue): UF or MUF. (\#): number of samples measured and averaged.

\begin{tabular}{lcc}
\hline $\begin{array}{l}\text { Tested } \\
\text { material }\end{array}$ & Layers & $\begin{array}{c}\text { Thickness } \\
\text { (mm) }\end{array}$ \\
\hline poplar_V & 1 & $2.2 \# 15$ \\
ceiba_V & 1 & $1.7 \# 10$ \\
poplar_P_UF & 3 & $5.4 \# 10$ \\
poplar_P_MUF & 5 & $9.3 \# 6$ \\
\hline
\end{tabular}

were carried out on the following experimental materials:

- veneers;

- plywood assembled before $H T$ and bonded with urea-formaldehyde (UF) resins;

- plywood assembled before $H T$ and bonded with melamine-urea-formaldehyde (MUF) resins;

Tab. 2 - The experimental matrix. Group codes indicate: species product glue treatment glue-application. For each group, test is the control sample. (Species): poplar or ceiba; (product): panel (P) or veneer (V); (glue): UF or MUF; (treatment): test, $5 \%$ of dry mass loss (T1) and 7\% of dry mass loss (T2). As regards bonding quality (EN 314-1): pre-treatment 5.1.1 means holding the specimens 24 hours in water at $20^{\circ} \mathrm{C}$, pre-treatment 5.1.2 means holding 6 hours the samples in boiling water and followed by cooling in water for at least 1 hour. The measured parameters are shear strength $\left(f_{v}\right)$ and wood fibre failure $(w f f)$. (\#): number of samples tested. (L-T): longitudinal and transversal samples according to EN314.

\begin{tabular}{lccll}
\hline Tested material & Layers & Panel thickness & Test EN 310 & Test EN 314-1 \\
\hline poplar_P_UF_test & 3 & $5.4 \# 10$ & $M O E-M O R(\mathrm{~L}-\mathrm{T})$ & $5.1 .1, f_{\mathrm{v}}, w f f$, acc \\
poplar_P_UF_T1_pre & 3 & $4.3 \# 10$ & $M O E-M O R(\mathrm{~L}-\mathrm{T})$ & $5.1 .1, f_{\mathrm{v}}, w f f$, acc \\
poplar_P_UF_T2_pre & 3 & $5.2 \# 10$ & $M O E-M O R(\mathrm{~L}-\mathrm{T})$ & $5.1 .1, f_{\mathrm{v}}, w f f$, acc \\
poplar_P_MUF_test & 5 & $9.3 \# 06$ & $M O E-M O R(\mathrm{~L}-\mathrm{T})$ & $5.1 .2, f_{\mathrm{v}}, w f f$, acc \\
poplar_P_MUF_T1_pre & 5 & $9.2 \# 02$ & $M O E-M O R(\mathrm{~L}-\mathrm{T})$ & $5.1 .2, f_{\mathrm{v}}, w f f$, acc \\
poplar_P_MUF_T2_pre & 5 & $9.1 \# 03$ & $M O E-M O R(\mathrm{~L}-\mathrm{T})$ & $5.1 .2, f_{\mathrm{v}}, w f f$, acc \\
poplar_P_MUF_test & 5 & $8.8 \# 10$ & $M O E-M O R(\mathrm{~L}-\mathrm{T})$ & $5.1 .2, f_{\mathrm{v}}, w f f$, acc \\
poplar_P_MUF_T1_post & 5 & $7.6 \# 10$ & $M O E-M O R(\mathrm{~L}-\mathrm{T})$ & $5.1 .2, f_{\mathrm{v}}, w f f$, acc \\
poplar_P_MUF_T2_post & 5 & $8.2 \# 06$ & $M O E-M O R(\mathrm{~L}-\mathrm{T})$ & $5.1 .2, f_{\mathrm{v}}, w f f$, acc \\
ceiba_P_MUF_test & 5 & $7.5 \# 04$ & $M O E-M O R(\mathrm{~L}-\mathrm{T})$ & $5.1 .2, f_{\mathrm{v}}, w f f$, acc \\
ceiba_P_MUF_T1_post & 5 & $7.3 \# 04$ & $M O E-M O R(\mathrm{~L}-\mathrm{T})$ & $5.1 .2, f_{\mathrm{v}}, w f f$, acc \\
\hline
\end{tabular}

${ }^{\circ} \mathrm{C} . M_{0}$ was considered as a reference for the following thermal treatments, where $M L_{0}$ is expressed as a $\%$ of $M_{0}$

Two heat treatments were applied: $T 1$ - up to a $M L_{0}$ of $\sim 5 \%$ - and $T 2$ - up to a $M L_{0}$ of $\sim 7 \%$ - laying the veneers and panels in an oven at $180-190{ }^{\circ} \mathrm{C}$ for different time periods. Panels were bonded using urea-formaldehyde (UF) and melamine-urea-formaldehyde (MUF) resin systems, respectively able to meet the requirements of bonding quality class 1 and 2 of EN 314, and hot pressed at $110{ }^{\circ} \mathrm{C}$ for 2 minutes at with a pressure of $0.6 \mathrm{MPa}$. Final panels satisfied the requirements of formaldehyde emission class E1 (EN 13986), complying with the national legislation (DM 2008). MUF resins were chosen since they are suitable for combining technical and economic feasibility. Testing was performed on UF glues as well for comparison.

Tab. 2 reports the complete set of panels each with its dimensions, number of layers and test performed. Panels glued before $H T$ (i.e., the glue line is thermally treated as well) are reported with the suffix pre, while panels glued after heat treatment (i.e., the glue line is not heat treated) are reported with the suffix post. The control samples are reported with_test.

Moisture content $(M C)$ and density of post panels were determined according to EN 322 and EN 323 technical standards. MC and density of pre panels were determined according to the above mentioned standards with the exception of the samples with larger dimensions, because the treatment was performed on the whole panel that was then divided into samples after the treatment.

MOE and MOR of the panels were determined on small specimens for longitudinal $(L)$ and transversal $(T)$ direction according to the EN 310 and EN 326-1 standards. Bonding quality was determined according to the

Tab. 3 - Heat-treated base materials and their main physical properties before and after the treatment. Group codes indicate: species pro duct_glue_treatment_glue-application. For each group, _test is the control sample. (Species): poplar or ceiba; (product): panel (P) or veneer (V); (glue): UF or MUF; (treatment): test, $5 \%$ of dry mass loss $(T 1)$ and $7 \%$ of dry mass loss (T2); glue application before heat treatment of the veneers ( $\_$pre) or after heat treatment of the veneers (_post). (\#): number of samples tested. Standard deviation (where available) is in brackets. (NA): not applicable.

\begin{tabular}{|c|c|c|c|c|c|c|c|c|c|}
\hline Type & $\begin{array}{l}\text { Tested } \\
\text { material }\end{array}$ & $\begin{array}{c}\rho_{12} \\
\text { pre treatment } \\
\left(\mathrm{kg} \mathrm{m}^{-3}\right)\end{array}$ & $\begin{array}{l}\text { Veneers } \\
\text { / Panels }\end{array}$ & $\begin{array}{c}\mathbf{T} \\
\left({ }^{\circ} \mathbf{C}\right)\end{array}$ & $\begin{array}{l}\text { Treat. Time } \\
\text { (hh) }\end{array}$ & $\begin{array}{l}\rho L_{12} \\
(\%)\end{array}$ & $\begin{array}{r}M L_{0} \\
(\%)\end{array}$ & $\begin{array}{r}M L_{12} \\
(\%)\end{array}$ & $\begin{array}{c}\text { Thickness } \\
\text { (mm) }\end{array}$ \\
\hline Heat & poplar_V_test & $327 \# 05(8)$ & V & - & - & - & - & - & - \\
\hline treated & poplar $\mathrm{V}^{-} \mathrm{T} 1$ & $319 \# 05$ (14) & $\mathrm{V}$ & 180 & 23 & NA & 5.7 & 8.3 & - \\
\hline \multirow[t]{3}{*}{ veneers } & poplar_V_T2 & $315 \# 05$ (8) & V & 180 & 33 & NA & 6.7 & 8.2 & - \\
\hline & ceiba $\overline{\mathrm{V}}$ test & $300 \# 05$ (16) & $\mathrm{V}$ & - & - & - & - & - & - \\
\hline & ceiba_V_T1 & $305 \# 05$ (11) & V & 180 & 23 & NA & 6.9 & 9 & - \\
\hline Heat & poplar_P_UF_test & $459 \# 10(10)$ & $\mathrm{P}$ & - & - & - & - & - & $5.4(0.1)$ \\
\hline treated & poplar_P_UF_T1_pre & $460 \# 05$ (4) & $\mathrm{P}$ & 180 & 23 & 6.5 & 4.6 & 7.9 & $5.3(0.0)$ \\
\hline \multirow[t]{4}{*}{ plywood } & poplar_P_UF_T2_pre & $454 \# 05$ (7) & $P$ & 180 & 33 & 7.0 & 6.2 & 8.9 & $5.2(0.1)$ \\
\hline & poplar_P_MUF_test & $454 \# 03$ (17) & $P$ & - & - & - & - & - & $9.4(0.1)$ \\
\hline & poplar_P_MUF_T1_pre & $459 \# 04$ (18) & $P$ & 190 & 8 & 7.0 & 4.9 & 9.8 & $9.0(0.0)$ \\
\hline & poplar_P_MUF_T2 pre & 474 \#02 (8) & $\mathrm{P}$ & 190 & 23 & 9.9 & 7.6 & 12.1 & $9.2(0.1)$ \\
\hline
\end{tabular}


EN 314 standard using the pre-treatment 5.1.1 for UF resins and 5.1.2 for MUF resins. Pre-treatment 5.1.1 consists of holding the specimens 24 hours in water at 20 ${ }^{\circ} \mathrm{C}$ before testing, and pre-treatment 5.1.2 consists of holding the samples 6 hours in boiling water followed by at least 1 hour in cold water. According to the EN 314, $f_{\mathrm{v}}$ and $A C W F$ were determined. Regarding $A C W F$ the EN 314 standard envisages to reject and repeat the tests where the failure occurs across the wood layers (i.e., perpendicularly to the glue line). In several cases, after treatment, the failure occurred perpendicularly to the glue line and the test could not be repeated due to the limited availability of specimens. In this case it was chosen to indicate the property as "non $E N A C W F$ ". Statistical analysis was performed using the R software (R Foundation, Vienna, Austria - http:// www.r-project.org/). The Mann-Whitney test for independent values, along with the Kruskal-Wallis non-parametric test and the pairwise Wilcoxon's test as a post-hoc, were used for the statistical analysis. The homoscedasticity was verified by a non-parametric Levene's test.

\section{Results and discussion}

\section{Physical characterization of the material}

$\rho_{12,} \rho L_{12}$ and $M L_{0}$ of veneers and panels glued before treatment ( pre) are reported in Tab. 3. Each of these data refer to the same samples before treatment (paired data). Once the veneers were treated they were assembled into plywood panels with MUF resins ( $p$ ost) and $\rho_{12}$ was determined. For post panels $\rho L_{12}$ refers control samples (independent data) and the results are reported in Tab. 4.

As displayed in Fig. 1, for veneers and panels glued before treatment, $\rho_{12}, M_{0}$ and $M_{12}$ show a clear reduction. The largest reduction affects $M_{12}$, the lower $M_{0}$. This observation confirms that part of the mass is loss due to cell wall components' degradation and part due to the lower $E M C$ after treatment at the same environmental conditions. $\rho L_{12}$ (where available) lays between $M L_{0}$ and $M L_{12}$, since a given $M L_{0}$ corresponds to a given permanent dimensional loss that finally results in a lower reduction of density as compared with that of the mass.

With regards to panels glued after treatment, in one case an increase of density is recorded (Tab. 4). This behavior is explained by the occurrence of permanent deformation during pressing operations (consequence of the reduction of the ultimate strength of the material after $H T$ ). In fact, as from Tab. 4, for the increased density a permanent reduction of thickness is observed if compared with the other treatments $(7.6 \mathrm{~mm}$ of poplar $T 1$ treatment against the $8.8 \mathrm{~mm}$ of the test
Tab. 4 - Panels realized by gluing heat treated veneers, main physical properties. Group codes indicate: species product glue treatment glue-application. For each group, test is the control sample. (Species): poplar or ceiba; (product): panel $(P)$ or veneer $(V)$; (glue): UF or MUF; (treatment): test, $5 \%$ of dry mass loss $(T 1)$ and $7 \%$ of dry mass loss $(T 2)$, glue application before heat treatment of the veneers (pre) or after heat treatment of the veneers ( post). (\#): number of samples tested. Standard deviation (where available) is in brackets.

\begin{tabular}{lcccc}
\hline Tested material & $\begin{array}{c}\boldsymbol{\rho}_{\mathbf{1 2}} \\
\left(\mathbf{k g ~ m}^{-\mathbf{3}} \mathbf{)}\right.\end{array}$ & $\begin{array}{c}\text { Veneers / } \\
\text { Panels }\end{array}$ & $\begin{array}{c}\boldsymbol{\rho} \boldsymbol{L}_{\mathbf{1 2}} \\
\mathbf{( \% )}\end{array}$ & $\begin{array}{c}\text { Thickness } \\
\mathbf{( m m )}\end{array}$ \\
\hline poplar_P_MUF_test & $490 \# 10(31)$ & $\mathrm{P}$ & - & $8.8(0.1)$ \\
poplar_P_MUF_T1_post & $496 \# 10(22)$ & $\mathrm{P}$ & -1.2 & $7.6(0.4)$ \\
poplar_P_MUF_T2_post & $457 \# 10(23)$ & $\mathrm{P}$ & 6.7 & $8.2(0.2)$ \\
ceiba_P_MUF_test & $401 \# 04(9)$ & $\mathrm{P}$ & - & $7.5(0.1)$ \\
ceiba_P_MUF_T1_post & $377 \# 04(15)$ & $\mathrm{P}$ & 6.0 & $7.3(0.1)$ \\
\hline
\end{tabular}

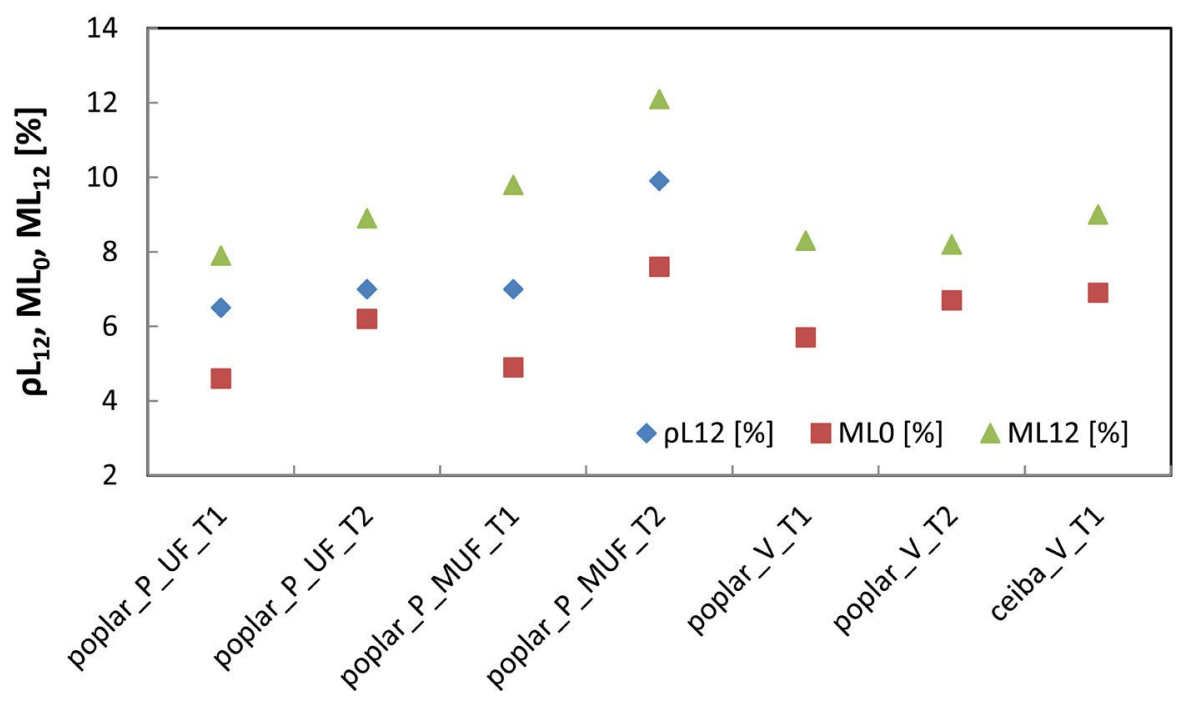

Fig. 1 - Graph of $\rho L_{12}$ (density loss at standard environmental conditions because of treatment), $M L_{0}$ (oven dry mass loss because of treatment) and $M L_{12}$ (mass loss because of treatment at standard environmental conditions) for different treatments and materials treated.

and 8.2 of $T 2$ treatment). This observation highlights a very relevant manufacturing problem for panels assembled after $H T$ process.

ence between $M L_{12}$ and $M L_{0}\left(\Delta M L_{12-0}\right)$ has shown to be sensitive to the material and not to the type of treatment. $T 1$ and $T 2$ treatments in fact have not shown statistically Among the analyzed parameters, the differ- significant differences by a Mann-Whitney

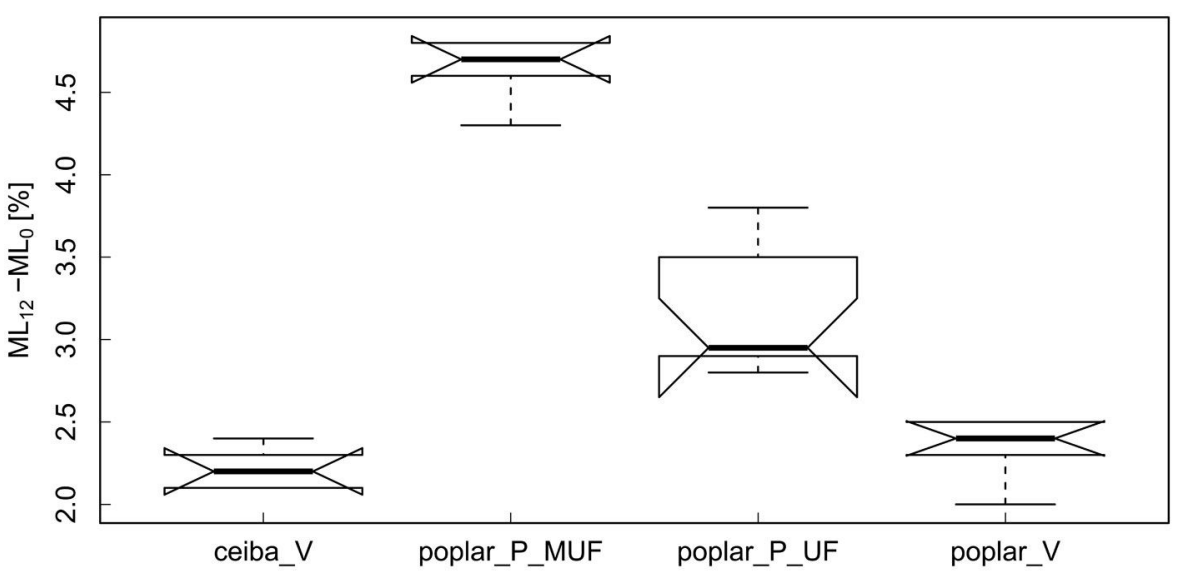

Fig. 2 - Difference between $M \mathrm{~L}_{12}$ (mass loss at standard environmental conditions) and $M L_{0}$ (mass loss at oven dry state) with $T 1$ and $T 2$ results pooled together. 
Tab. 5 - Mechanical performances of treated and test panels according to EN 310. (_post): glued after thermal treatment; (_pre): glued be fore treatment. (NV): non-valid value because all the specimens tested were broken outside the time window of $60 \pm 30$ seconds prescribed by the EN 310. (\#): number of samples tested.

\begin{tabular}{|c|c|c|c|c|c|c|c|c|}
\hline Tested material & MOE L (MPa) & Group & MOR L (MPa) & Group & MOE T (MPa) & Group & MOR T (MPa) & Group \\
\hline poplar_P_UF_test & $7993 \# 28$ & $\mathrm{a}$ & $66 \# 30$ & $\mathrm{a}$ & NV & NV & $18 \# 22$ & $\mathrm{a}$ \\
\hline poplar P UF T1 pre & $7616 \# 3$ & $\mathrm{a}$ & $47 \# 18$ & $\mathrm{~b}$ & NV & NV & $11 \# 14$ & $\mathrm{~b}$ \\
\hline poplar_P_UF_T2_pre & NV & NV & $45 \# 18$ & $\mathrm{~b}$ & NV & NV & $8 \# 14$ & $\mathrm{~b}$ \\
\hline poplar_P_MUF test & $5448 \# 30$ & $\mathrm{a}$ & $48 \# 30$ & $\mathrm{a}$ & $3123 \# 30$ & $\mathrm{a}$ & $33 \# 30$ & $\mathrm{a}$ \\
\hline poplar P MUF T1 pre & $4924 \# 18$ & $\mathrm{a}$ & $30 \# 18$ & $\mathrm{~b}$ & $3020 \# 18$ & $\mathrm{a}$ & $23 \# 12$ & $\mathrm{~b}$ \\
\hline poplar_P_MUF_T2 pre & $5471 \# 12$ & $\mathrm{a}$ & $23 \# 18$ & $\mathrm{c}$ & 2947 \#4 & $\mathrm{a}$ & $15 \# 12$ & $\mathrm{c}$ \\
\hline poplar P MUF Test & $6507 \# 6$ & $\mathrm{a}$ & $51 \# 6$ & $\mathrm{a}$ & $2304 \# 6$ & $\mathrm{a}$ & $30 \# 6$ & $\mathrm{a}$ \\
\hline poplar_P_MUF_T1_post & $6496 \# 12$ & $\mathrm{a}$ & $38 \# 12$ & $\mathrm{~b}$ & $2143 \# 12$ & $\mathrm{a}$ & $19 \# 12$ & b \\
\hline poplar_P_MUF_T2_post & $6335 \# 6$ & $\mathrm{a}$ & $35 \# 6$ & $\mathrm{~b}$ & $2029 \# 6$ & $\mathrm{a}$ & $18 \# 6$ & $\mathrm{~b}$ \\
\hline ceiba_ $\overline{\mathrm{P}} \overline{\mathrm{M}} \mathrm{MF}$ test & $3447 \# 3$ & $\mathrm{a}$ & $37 \# 3$ & $\mathrm{a}$ & $1178 \# 3$ & $\mathrm{a}$ & $18 \# 3$ & $\mathrm{a}$ \\
\hline ceiba ${ }^{-} \mathrm{PUF}^{-} \mathrm{T} 1$ post & $3645 \# 3$ & a & $24 \# 3$ & $\mathrm{~b}$ & $1268 \# 2$ & a & $13 \# 3$ & $\mathrm{~b}$ \\
\hline
\end{tabular}

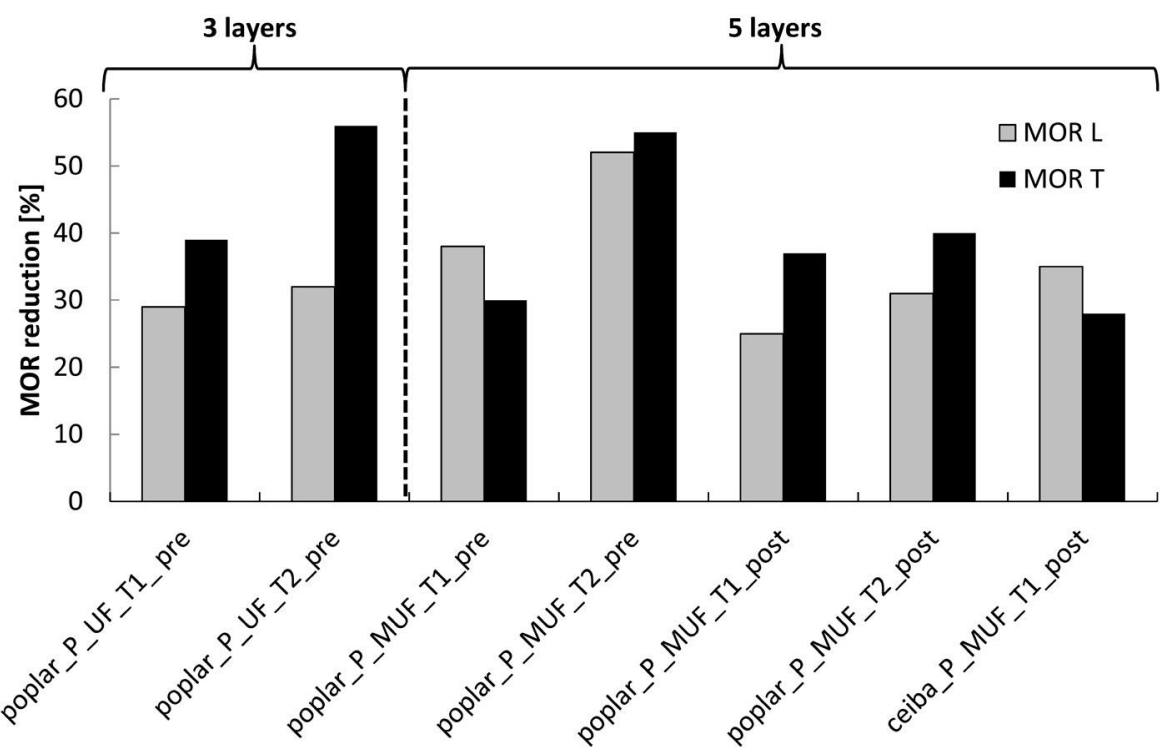

Fig. 3 - MOR reductions for transversal and longitudinal specimens referred to test samples.

test for independent values. $T 1$ and $T 2$ between the different materials used. A pairgroups were then analyzed together using a wise Wilcoxon's test for independent values Kruskal-Wallis non-parametric test, high- used as post-hoc test has shown statistically lighting statistically significant differences significant differences between all the

Tab. 6 - Bonding performances of treated and test panels according to EN 314. (post): glued after thermal treatment; (_pre): glued before treatment; $\left(f_{\mathrm{v}}\right)$ : shear strength; $(A C W F)$ : percentage of apparent cohesive wood failure. (\#): number of samples tested.

\begin{tabular}{lccccc}
\hline Tested material & Test & $\begin{array}{c}\boldsymbol{f}_{\mathbf{v}} \\
\text { (MPa) }\end{array}$ & Group & $\begin{array}{c}\text { non EN } \\
\boldsymbol{A} \boldsymbol{C} \boldsymbol{W F} \\
\mathbf{( \% )}\end{array}$ & Group \\
\hline poplar_P_UF_test & 5.1 .1 & $0.9 \# 24$ & $\mathrm{a}$ & 90 & $\mathrm{a}$ \\
poplar_P_UF_T1_pre & 5.1 .1 & $0.3 \# 12$ & $\mathrm{~b}$ & 86 & $\mathrm{a}$ \\
poplar_P_UF_T2_pre & 5.1 .1 & $0.2 \# 12$ & $\mathrm{~b}$ & 90 & $\mathrm{a}$ \\
poplar_P_MUF_test & 5.1 .2 & $1.3 \# 45$ & $\mathrm{a}$ & 36 & $\mathrm{a}$ \\
poplar_P_MUF_T1_pre & 5.1 .2 & $0.4 \# 45$ & $\mathrm{~b}$ & 100 & $\mathrm{~b}$ \\
poplar_P_MUF_T2_pre & 5.1 .2 & $0.3 \# 30$ & $\mathrm{c}$ & 100 & $\mathrm{~b}$ \\
poplar_P_MUF_test & 5.1 .2 & $1.4 \# 18$ & $\mathrm{a}$ & 57 & $\mathrm{a}$ \\
poplar_P_MUF_T1_post & 5.1 .2 & $0.5 \# 30$ & $\mathrm{~b}$ & 88 & $\mathrm{~b}$ \\
poplar_P_MUF_T2_post & 5.1 .2 & $0.6 \# 18$ & $\mathrm{~b}$ & 97 & $\mathrm{~b}$ \\
ceiba_P_MUF_test & 5.1 .2 & $0.8 \# 12$ & $\mathrm{a}$ & 100 & $\mathrm{a}$ \\
ceiba_P_MUF_T1_post & 5.1 .2 & $0.3 \# 12$ & $\mathrm{~b}$ & 100 & $\mathrm{a}$ \\
\hline
\end{tabular}

groups except between poplar and ceiba, both to be considered as massive wood (Fig. 2).

Fig. 2 displays how the heat treatment of massive wood corresponds to a cell wall degradation that leads to a $\Delta M L_{12-0}$ of about $2-2.5 \%$. In the case of the panels glued before heat treatment the degradation leads to about a $3 \%$ difference for panels glued with UF resins and to about a $4.5 \%$ difference for panels glued with MUF resins. This can be explained by different behaviors in the recollocation of water between massive wood and glues, with a measurable difference between UF and MUF glues.

\section{Mechanical characterization of the material}

Longitudinal $(L)$ and transversal (T) $M O E$ and $M O R$ results are summarized in Tab. 5 . The non-valid (NV) values reported therein are due to the fact that none of tested specimens was broken within the time of $60 \pm 30$ seconds required by the EN 310 standard. For every material, values of the treated samples were compared with the control sample by means of Kruskal-Wallis non-parametric test. Where statistically significant, differences were highlighted, and a Pairwise Wilcoxon test for independent values was performed. Statistical analyses revealed no significant differences among MOEs, for either $L$ or $T$ samples. For $M O R$, a statistically significant difference was observed among the controls, and both $T 1$ and $T 2$ treatments and in some case differences between $T 1$ and $T 2$ were highlighted too.

Based on statistical analysis, no significant differences arose on $M O E$ after $H T$, while for $M O R$ relevant reductions were detected. $M O R$ reductions, both for $L$ and $T$ samples, are reported in Fig. 3. As a general rule, post (glued after treatment) panels present better performances than pre (glued before treatment) panels, and in some cases it is documented that $T 2$ treatment results in a higher $M O R$ reduction if compared to $T 1$ treatment. For UF resins, the transversal 
samples present larger MOR reductions when compared to longitudinal samples, even though it cannot be determined whether this is a consequence of the resins or of the number of layers. As for MUF resins, post panels presented better results than pre panels.

\section{Bonding quality}

Bonding quality was tested according to EN 314-1, 2 standards with 5.1.1 protocol for UF resins and 5.1.2 protocol for MUF resins. The main results are summarized in Tab. 6. For every case the treated panels showed a lower $f_{\mathrm{v}}$ than control panels. Such differences were determined to have statistical significance by a Kruskal-Wallis test and by a pairwise Wilcoxon's test for independent values as post-hoc test. Both $T 1$ and $T 2$ presented statistically significant differences with the control sample and in one case even differences between $T 1$ and $T 2$ treatments could be detected

Fig. 4 shows the reduction of $f_{\mathrm{v}}$ after $T 1$ and $T 2$ referred to the control sample. The $f_{\mathrm{v}}$ reduction for MUF resins, though tested following the 5.1.2 protocol, is in line with the reduction of UF resins, tested following the 5.1.1 protocol. This $f_{\mathrm{v}}$ reduction can be ascribed to the decreased wood mechanical properties, to the thermal degradation of the glues during $H T$ for pre panels and to the lower adhesion properties of glues to the heat-treated wood for post panels.

In order to understand the influence of the thermal treatment on the glue and on the wood, respectively, $A C W F$ was determined. As already mentioned, $A C W F$ was determined with some differences with respect to the EN 314 standard and it is mentioned as "non EN ACWF". Results are reported in Fig. 5, and can be summirized as follows:

- UF poplar panels glued before $H T$ show a high value of non EN ACWF for the control and for both $T 1$ and $T 2$ treatments. This means that the treatment affects the glue and the wood in a similar way.

- MUF poplar panels glued before $H T$ present a lower non EN ACWF if compared with $T 1$ and $T 2$. This indicates that the failure occurs mainly on the glue instead of the wood, and that the $H T$ determines a larger degradation of wood than of the glue resulting in an increased non $E N A C W F$.

- MUF poplar panels glued after $H T$ show a trend very similar to MUF panels glued before heat treatment, indicating that this behavior is mainly dependent upon the wood rather than the glues.

- MUF ceiba panels glued after treatment both for treated or untreated samples permanently break on wood, indicating that for ceiba the strength of material is the prominent problem compared to glues degradation.

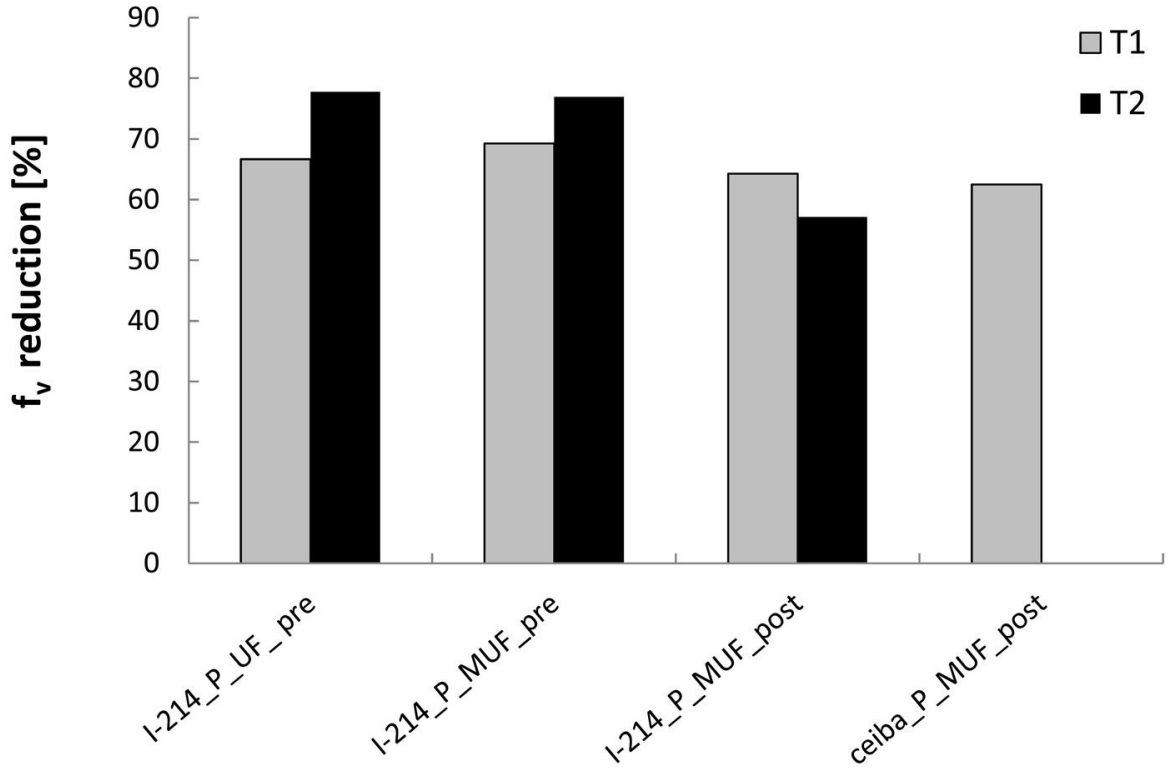

Fig. 4 - Shear strength reduction of panels with different treatments as referred to a control sample, after EN 314 method.

\section{Conclusions}

Treated panels have shown mass and density reductions at dry state, after treatment, as well as at standard environmental conditions after re-moisturizing. The loss in dry mass resulted lower than that at standard environmental conditions and to that of density, indicating that the loss in cell wall polymers (e.g., hemicellulose) determined by the treatment significantly affects EMC.

As far as $M L_{12}$ and $M L_{0}$ are concerned, the difference between the two values of mass was dependent on the type of products treated (massive wood, MUF panels glued before treatment and UF panels glued before treatment). However, differences in mass

losses within the same product were constant (not significant differences) either after treatment $T 1$ or $T 2$, suggesting that the treated material is more important than the treatment intensity.

On each product, both the treatment and its intensity showed a significant influence on $M O R$, but no influence on $M O E$ values was observed (variations not statistically significant). Differences in $M O R$ values were always present between the control and the treated samples in all the directions tested, but only occasionally between the two treatments' intensity ( $T 1$ and $T 2$ ). The higher MOR loss was detected for samples glued before $H T$ as compared with samples glued

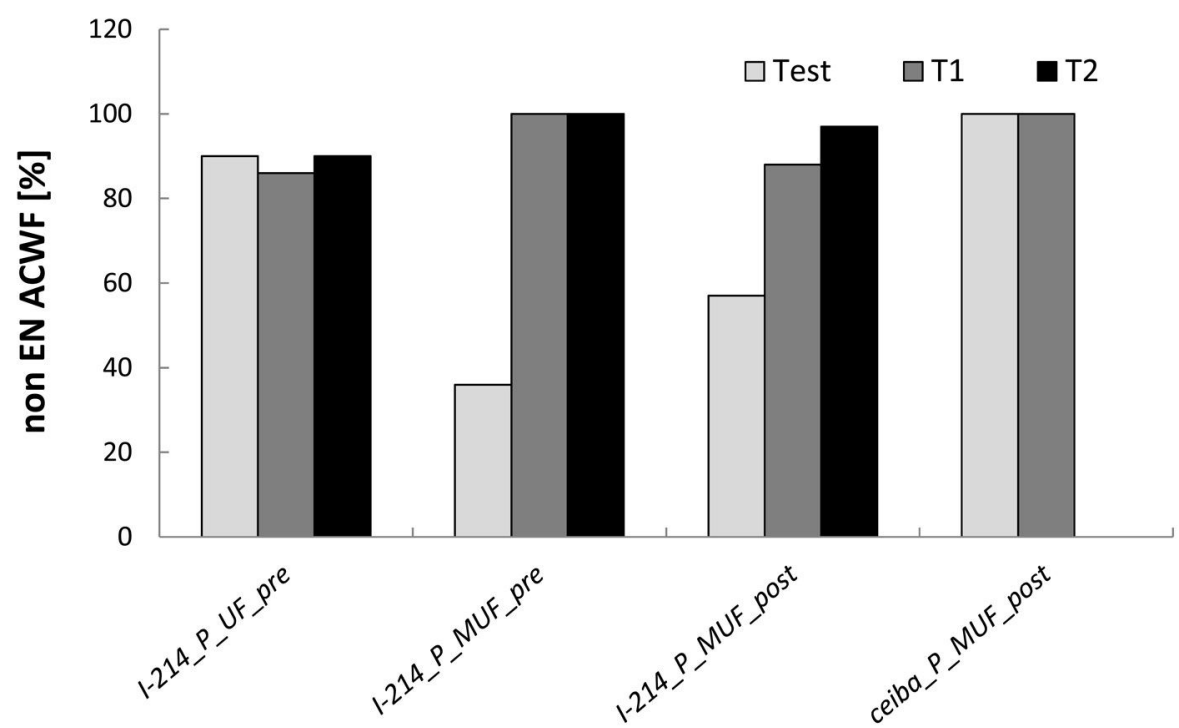

Fig. 5 - Percentage of apparent cohesive wood failure for the control samples and groups of samples subjected to different heat treatments. 
after treatment.

Large reductions of shear strength were observed even with better results for the specimens glued after treatment compared with specimens glued before treatment.

Apparent cohesive wood failure shows that different degradations affect wood and glues with a prominent effect on glues for UF resins and a prominent effect on the wood for MUF resins.

\section{Acknowledgements}

The authors acknowledge the financial support of the Regional Administration of Tuscany through the POR $\mathrm{CReO}$ project line, as well as the FESR.

\section{References}

Bak M, Németh R (2012). Changes in swelling properties and moisture uptake rate of oil-heattreated poplar (Populus $x$ Euramericana cv. Pannónia) wood. Bioresources 7 (7): 5128-5137. - doi: 10.15376/biores.7.4.5128-5137

DM (2008). Italian Ministerial Decree DM 10.10. 2008. Dispositions for regulating formaldehyde emission from wood based panels and their products in life and stay environments. Ministero del Lavoro, della Salute e delle Politiche sociali, Roma, Italy, pp. 5 [in Italian].

EN 310 (1994). Wood-based panels - Determination of modulus of elasticity in bending and of bending strength. CEN, European Committee for Standardization, Brussels, Belgium, pp. 9. [online] URL: http://standards.cen.eu/dyn/www/f?p $=$ CENWEB: 105

EN 314-1.2 (2005). Plywood - Bonding quality -
Part 1: Test methods. CEN, European Committee for Standardization, Brussels, Belgium, pp. 21. [online] URL: http://standards.cen.eu/dyn/www/ $\mathrm{f} ? \mathrm{p}=\mathrm{CENWEB}: 105$

EN 322 (1994). Wood-based panels - Determination of moisture content. CEN, European Committee for Standardization, Brussels, Belgium, pp. 4. [online] URL: http://standards.cen.eu/ dyn/www/f?p=CENWEB:105

EN 323 (1994). Wood based panels - Determination of density. CEN, European Committee for Standardization, Brussels, Belgium, pp. 4. [online] URL: http://standards.cen.eu/dyn/www/f?p $=$ CENWEB: 105

EN 326-1 (1995). Wood based panels. Sampling, cutting and inspection. Sampling and cutting of test pieces and expression of test results. CEN, European Committee for Standardization, Brussels, Belgium, pp. 12. [online] URL: http://standards.cen.eu/dyn/www/f?p=CENWEB: 105

EN 13986 (2004). Wood-based panels for use in construction. Characteristics, evaluation of conformity and marking. CEN, European Committee for Standardization, Brussels, Belgium, pp. 54. [online] URL: http://standards.cen.eu/dyn/ www/f?p=CENWEB: 105

Finnish ThermoWood Association (2003). ThermoWood handbook. Finnish ThermoWood Association, Helsinki, Finland, pp. 66.

Kamdem DP, Pizzi A, Jermannaud A (2002). Durability of heat-treated wood. Holz als Rohund Werkstoff 60 (1): 1-6. - doi: 10.1007/s0010 7-001-0261-1

Navi P, Sandberg D (2012). Thermo-hydro-mechanical processing of wood. EPFL Press, Lausanne, Switzerland, pp. 280. [online] URL:
http://books.google.com/books?id=wO3-HP51CXoC

Nazerian M, Ghalehno MD (2011). Physical and mechanical properties of laminated veneer lumber manufactured by poplar veneer. Journal of Agricultural Science and Tecnology A 1:10401045. [online] URL: http://www.davidpublishing.com/davidpublishing/Upfile/12/22/2011/201 1122280751601.pdf

Paul W, Ohlmeyer M, Leithoff H (2006). Thermal modification of OSB-strands by a one-step heat pre-treatment - Influence of temperature on weight loss, hygroscopicity and improved fungal resistance. Holz als Roh- und Werkst 65:57-63. doi: 10.1007/s00107-006-0146-4

Poncsák S, Shi SQ, Kocaefe D, Miller G (2007). Effect of thermal treatment of wood lumbers on their adhesive bond strength and durability. Journal of Adhesion Science and Technology 21 (8): 745-754. - doi: 10.1163/156856107781362653

Sandberg D, Haller P, Navi P (2013). Thermo-hydro and thermo-hydro-mechanical wood processing: an opportunity for future environmentally friendly wood products. Wood Material Science and Engineering 8 (1): 64-88. - doi: 10.1080/174 80272.2012 .751935

Sernek M, Boonstra M, Pizzi A, Despres A, Gérardin $P$ (2008). Bonding performance of heat treated wood with structural adhesives. Holz als Roh- und Werkstoff 66 (3): 173-180. - doi: 10.1007/s00107-007-0218-0

Taghiyari HR (2011). Study on the effect of nanosilver impregnation on mechanical properties of heat-treated Populus nigra. Wood Science and Technology 45 (2): 399-404. - doi: 10.1007/s00 226-010-0343-5 